\title{
Promise and Pitfalls of Endemic Resistance for Cultural Resources Threatened by Phytophthora ramorum
}

\author{
Richard C. Cobb, ${ }^{1, \dagger}$ Noam Ross, ${ }^{2}$ Katherine J. Hayden, ${ }^{3,4}$ Catherine A. Eyre, ${ }^{4}$ Richard S. Dodd, ${ }^{4}$ \\ Susan J. Frankel, ${ }^{5}$ Matteo Garbelotto, ${ }^{4}$ and David M. Rizzo ${ }^{6}$ \\ ${ }^{1}$ Department of Natural Resources \& Environmental Science, California Polytechnic State University, San Luis Obispo 93407, U.S.A.; \\ ${ }^{2}$ EcoHealth Alliance, 460 W 34th St, New York 10001, U.S.A.; ${ }^{3}$ Royal Botanic Garden Edinburgh, 20a Inverleith Row, Edinburgh, EH3 5LR, \\ United Kingdom; ${ }^{4}$ Department of Environmental Science, Policy and Management, University of California-Berkeley 94720, U.S.A.; ${ }^{5}$ Pacific \\ Southwest Research Station, 800 Buchanan Street, Albany, CA 94710, U.S.A.; and ${ }^{6}$ Department of Plant Pathology, University of California, \\ One Shields Ave., Davis 95616, U.S.A.
}

Accepted for publication 1 October 2018.

\begin{abstract}
Invasive forest pathogens can harm cultural, economic, and ecological resources. Here, we demonstrate the potential of endemic tree pathogen resistance in forest disease management using Phytophthora ramorum, cause of sudden oak death, in the context of management of tanoak (Notholithocarpus densiflorus), an ecologically unique and highly valued tree within Native American communities of northern California and southern Oregon in the United States. We surveyed resistance to P. ramorum on the Hoopa Valley Indian Reservation and Yurok Indian Reservation in a set of study sites with variable management intensities. Variation in resistance was found at all sites with similar mean and variation across stands, and resistance tended to have a random spatial distribution within stands but was not associated with previous stand management (thinning or prescribed fire) or structural characteristics such as tree density, basal area, or pairwise relatedness among study trees. These results did not suggest host, genetic, management, or environment interactions that could be easily leveraged into treatments to increase the prevalence of resistant trees. We applied epidemiological models to assess the potential application of

endemic resistance in this system and to examine our assumption that in planta differences in lesion size-our measure of resistance-reflect linkages between mortality and transmission (resistance) versus reduced mortality with no change in transmission (tolerance). This assumption strongly influenced infection dynamics but changes in host populationsour conservation focus-was dependent on community-level variation in transmission. For P. ramorum, slowing mortality rates (whether by resistance or tolerance) conserves host resources when a second source of inoculum is present; these results are likely generalizable to pathogens with a broader host range. However, when the focal host is the sole source of inoculum, increasing tolerant individuals led to the greatest stand-level pathogen accumulation in our model. When seeking to use variation in mortality rates to affect conservation strategies, it is important to understand how these traits are linked with transmission because tolerance will be more useful for management in mixed-host stands that are already invaded, compared with single-host stands with low or no pathogen presence, where resistance will have the greatest conservation benefits.
\end{abstract}

Protecting forests against invasion by virulent, broad-host-range invasive pathogens is often a losing battle (Filipe et al. 2012; Freinkel 2007; Maloy 1997). Abundant secondary or primary hosts, survival in the environment, and a wide range of plants that support pathogen spread result in rapid establishment of microbial invaders. When one or more hosts support pathogen reproduction and transmission but do not suffer deleterious consequences of infection, spread to hosts killed by the pathogen may be unconstrained by negative evolutionary or epidemiological feedbacks (Cobb et al. 2010; Garbelotto and Hayden 2012; Holt et al. 2003). This epidemiological scenario can create significant plant conservation problems, including rapid and widespread tree mortality as well as increased risk of extinction (Smith et al. 2006). Such forest pathogens can rapidly expand beyond the efficacy of actions such as eradication treatments, quarantines, and prevention of spread across host-free barriers (Cunniffe et al. 2016; Thompson et al. 2016). Although well-organized and committed suppression campaigns for these pathogens can reduce spread rates (Hansen et al. 2008), at best, these efforts provide time

${ }^{\dagger}$ Corresponding author: R. C. Cobb; E-mail: rccobb@calpoly.edu

Funding: This work was supported by USDA Forest Service, Forest Health Protection, Special Technology Development Program.

The author(s) declare no conflict of interest.

This article is in the public domain and not copyrightable. It may be freely reprinted with customary crediting of the source. The American Phytopathological Society, 2019. to develop management approaches that protect standing ecological, economic, or cultural resources.

Tree breeding programs have been successful in increasing individual resistance to invasive microbial pathogens and can provide a long-term, restoration-focused management strategy for forest diseases (Sniezko 2006). However, increasing resistance through breeding is a long-term undertaking because of the long lifespan and time to maturity of forest trees. This creates a mismatch between immediate threats to cultural and ecological resources and the relatively longer time scales needed for effective resistance to be developed. Here, we evaluate a related but alternative approach: the use of endemic patterns of resistance as a means of conserving specific cultural resources. Identification of resistant phenotypes is of central importance in development of breeding programs and a crucial part of long-term tree resilience (Hayden et al. 2011; Maloy 1997; Sniezko 2006). However, this approach overlooks the nearterm problem of threats to specific cultural resources as well as any proactive silvicultural role in leveraging endemic patterns of resistance (Bowcutt 2011). Can endemic pathogen resistance be leveraged as a short-term management tool for diseases where spread and impacts appear to be uninhibited by host genetic or spatial variation? Can endemic patterns of resistance also be employed to conserve threatened hosts on the time scales of pathogen invasion? The answer to these questions will likely hinge on the nature of resistance within individuals, its frequency and strength in host populations, and epidemiological drivers at the community scale.

Here, we examine the potential and pitfalls of employing endemic patterns of resistance to an invasive pathogen with a case 
study of Phytophthora ramorum, the cause of sudden oak death, a devastating disease of tanoak (Notholithocarpus densiflorus). $P$. ramorum is a broad-host-range pathogen, with asymmetric impacts and transmission among host species (Garbelotto and Hayden 2012). This pathogen of unknown origin emerged circa 1995 in central coastal California as a cause of mortality on tanoak and Quercus spp. in the red oak clade (Rizzo et al. 2005). $P$. ramorum spread occurs via rain splash at scales less than $15 \mathrm{~m}$ and wind-driven rain at scales up to $2,000 \mathrm{~m}$, creating a multiscale epidemiological and management challenge (Davidson et al. 2011; Mascheretti et al. 2008; Rizzo et al. 2005). Within California, spread rates are increasing as inoculum accumulates within landscapes (Cunniffe et al. 2016). However, the most extensive at-risk landscapes are located along the north coast, where pathogen invasion is still in an early stage and the value of at-risk tanoak populations varies greatly among forest stakeholders (Bowcutt 2011; Cobb et al. 2013; Meentemeyer et al. 2011).

Threatened northern California tanoak populations represent a conflicting set of social perspectives on the importance of the disease and the value of the most severely impacted host tree. Coastal northern California forests include many highly productive and economically important timber stands, with a regional forest industry centered principally on redwood, Douglas-fir, and ponderosa pine (Sequoia sempervirens, Pseudotsuga menziesii, and Pinus ponderosa, respectively) (Bowcutt 2011). Broad-leaved species, most prominently tanoak, are often targeted for herbicide suppression and several decades of research has focused on refining chemical applications to reduce competition with coniferous timber species (Harrington and Tappeiner 2009). Tanoak is valued very differently by indigenous California Indian communities, where the tree is a source of traditional food and medicine, and holds an important place in religious practice and worldview (Bowcutt 2013). Contrasting perspectives on the value of tanoak have created pointed conflict between the region's indigenous people and commercial timber interests, manifested as protests over herbicide use on traditional territories and the banning of herbicides on tribal lands by public referendum (Bowcutt 2011, 2013). The emergence of sudden oak death has created an additional challenge to the provisioning of tanoak cultural resources, because the pathogen is poised to spread rapidly through traditional gathering areas and tribal land holdings. These resources are threatened in the near term, meaning that specific resources (trees, stands, and gathering areas) cannot be protected or maintained by breeding programs, which require years or decades to achieve efficacy at the stand level. Endemic variation in tanoak resistance to Phytophthora ramorum has been demonstrated in several stands but it is unclear if or how resistance could be used to protect these resources (Garbelotto and Hayden 2012).

Previous research has demonstrated tanoak traits associated with resistance to $P$. ramorum, including variation in pathogen growth rate in detached tanoak leaves and twigs (Hayden et al. 2011). A subsequent study showed that slower in planta pathogen growth rates measured in the laboratory are associated with lower likelihood of infection and greater tanoak sapling survival under natural inoculation conditions (Hayden et al. 2013). Limitation of pathogen growth rates in planta can be linked to slower pathogen spread rates in populations when transmission is limited by the amount of infected tissue (Roy and Kirchner 2000). However, variation in mortality rates can emerge from two distinct epidemiological scenarios. In the first, linkages occur among in planta growth rates, transmission (sporulation), and mortality rate; this condition is properly termed resistance. In the second, infection effects on host fitness-particularly mortality rate-have weaker links to transmission; this condition is properly termed tolerance (Best et al. 2014; Desprez-Loustau et al. 2016). Although both resistance and tolerance have potential application to host conservation, they have different impacts on pathogen populations (Garbelotto and Hayden 2012; Hayden et al. 2013). In this study, we conducted the first set of stand-level surveys of tanoak resistance to $P$. ramorum as measured in detached leaves from trees in the wild and with sampling across a broad landscape area. Our current methodology does not resolve whether the measurements reflect resistance or tolerance as we have defined them here; therefore, we evaluate this assumption within a modeling analysis meant to simulate proactive management based on the field data and the priorities of tribal stakeholders.

Previous field surveys have documented partial resistance in tanoak to $P$. ramorum; here, all surveyed plants were susceptible but, in each case, resistance occurred on a continuum among individuals and was randomly distributed within the sampled population (Hayden et al. 2011). Although the physiological, structural, or biochemical mechanisms conferring the resistance phenotype in tanoak are not known, published data are consistent with a multigenic trait, which reduces sporulation rather than reducing infectious period directly (Hayden et al. 2013). Variation in resistance is very likely to occur in high-cultural-value tanoak stands, including those where active thinning and prescribed fire are regularly employed to promote nontimber resources such as acorn production. Given that the disease threatens these resources on a timescale much shorter than that required for development and deployment of resistant stock, protecting imminently threatened stands may be facilitated by understanding the frequency of resistance therein and identifying the causes of variation among them.

Here, we worked in collaboration with the Hoopa and Yurok tribes to identify the range of resources and management strategies representative of tanoak stands threatened by $P$. ramorum in locations where management actions often focus on this tree's great cultural significance. We evaluated endemic levels of resistance across stands that vary in terms of tree density, species composition, and tree size distribution resulting from variation in controlled burning and tree-thinning applied by tribal forest management agencies. We used this plot network to evaluate the frequency, stand structure, and individual tree characteristics associated with tanoak resistance to $P$. ramorum. We then employed a flexible forest disease model (Cobb et al. 2012, 2017) to (i) forecast the effects of endemic patterns of resistance on tanoak density should these stands become invaded, (ii) examine the implications of our assumption of resistance versus tolerance on sudden oak death epidemiology, and (iii) explore the promise of an endemic resistance-based management strategy. We conducted this model analysis for single and multihost transmission scenarios that greatly influence within-stand disease severity and pathogen distribution across the landscape (Cobb et al. 2012; Cunniffe et al. 2016; Filipe et al. 2012). Under what circumstances is endemic resistance an effective means of protecting or sustaining cultural resources threatened by P. ramorum? Are typical frequencies or spatial patterns of tanoak resistance to $P$. ramorum influenced by stand structure, or individual tree characteristics such as size, health status, or canopy position? We addressed these questions with a linked field and modeling study of endemic patterns of tanoak resistance to $P$. ramorum in culturally important tanoak stands in Northern California.

\section{MATERIALS AND METHODS}

Study sites and field sampling. The Hoopa and Yurok reservations are located in Humboldt and Del Norte Counties, respectively, of northern coastal California. The Yurok Indian Reservation and greater Yurok traditional lands include coastal areas and inland forests, where stands utilized for tanoak acorn collection have been maintained from the aboriginal period to the present. The Hoopa Valley Indian Reservation is located entirely within inland forest types and similarly includes numerous tanoak stands also maintained as acorn collection areas for a period of at least centuries if not millennia (Bowcutt 2013; Waterman 1920). Study sites were selected through a series of site visits with tribal 
forest managers and tribal members in July 2013 (Fig. 1). Ten study sites were selected to span the geographical range of tanoak within the borders of the reservations and were distributed across a spatial area of approximately $50 \mathrm{~km}$. The nearest known invasions of $P$. ramorum were located within $10 \mathrm{~km}$ of each reservation's borders and many other stands of cultural importance (Valachovic et al. 2013). As of 2018, neither of the reservations are known to be invaded but $P$. ramorum has continued to encroach on these lands and invasion is expected in the next decade (Cunniffe et al. 2016). Pathogen-invaded stands are likely to be better locations for rapidly identifying the most resistant individuals if disease progressively removes tanoak according to their resistance. The problem we confront focuses directly on stands which have not yet been invaded and whether host resistance is an effective tool for protecting their value in the context of indigenous communities and in the near term. We conducted preliminary visits to 18 stands and excluded those with native pathogen impacts (frequently Armillaria root disease). Ultimately, we selected 10 stands which represented a range of preexisting management actions. Prior stand treatments included no management in the historical period (two stands), single-entry fuel-reduction thinning, known as thinning from below (removal of small diameter trees) (five stands), to regular thinning and burning (every approximately 5 years) in old-growth tanoak nut-tree groves where clearing is implemented with the aim of creating a low-density stand with high species diversity and complex canopy structure to promote acorn yields (three stands). Study site selection was guided by input from tribal members to reflect areas which are of specific cultural value, are unlikely to have commercial timber harvests, and which represent a continuous range of species composition and density (Fig. 1). These choices created the opportunity to examine patterns of resistance within and between stands on a gradient as opposed to a design with replication of specific treatments.

At each site, five variable-radius plots were established in crossshaped pattern in a $1-\mathrm{ha}^{2}$ area to assess basal area and stem density by species. Sixteen tanoak trees were selected for assessment of resistance within a 60-by-60-m grid located in the center of the area surveyed for forest structure. These focal study trees have tree-totree distances of at least $15 \mathrm{~m}$, a spacing which exceeds the average scale of tanoak clonality (Dodd et al. 2012). Tree selection was stratified such that a range of tree health, canopy position, and tree size were represented within each study site. In addition, two to four trees were selected for resistance assessment without constraint of spacing between study trees. This additional sampling was aimed at increased representation of individual tree characteristics within each site; for example, by insuring that trees of small size classes were sampled at each study site and to include some trees at spacing less than $15 \mathrm{~m}$. Each study tree was mapped with a GPS to within at least 1-m spatial accuracy and photographed, and each stem was measured for diameter at breast height $(1.3 \mathrm{~m})$. Additionally, each tree was measured for height with a laser range finder, given a broad health rating (good, fair, or poor), and assigned a canopy position (suppressed understory, suppressed intermediate, codominant,

\section{Field: Collaborative study design and site selection}

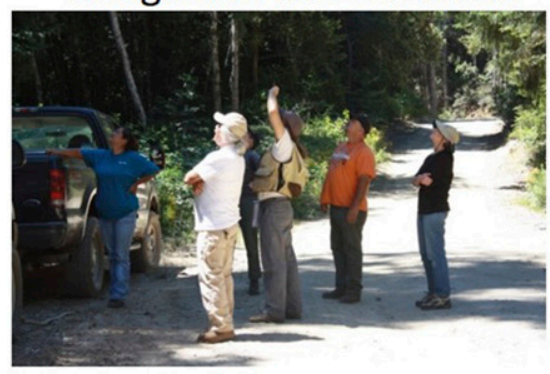

Photograph and measure lesions using high-contrast image analysis - two mock (control) inoculations shown

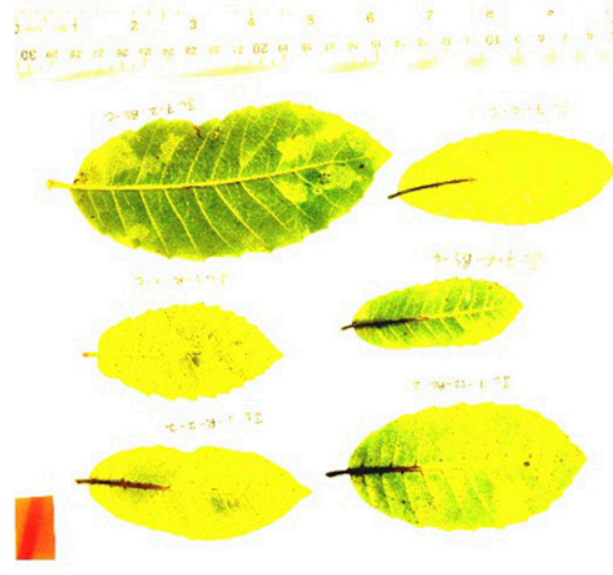

Sample in stands representing a gradient of management, species, and size class structure
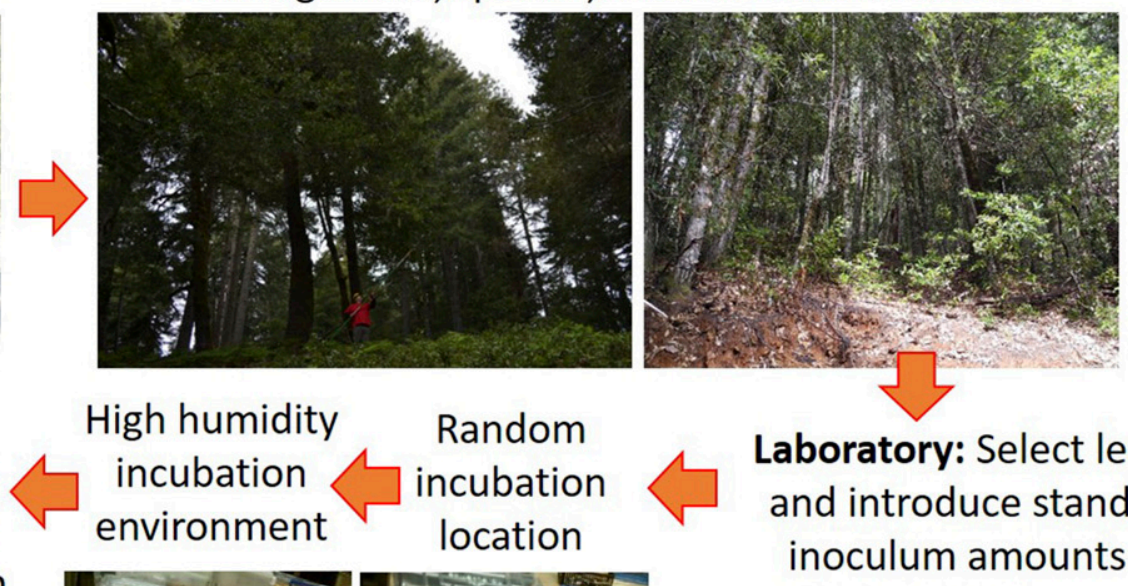

Laboratory: Select leaves and introduce standard inoculum amounts at
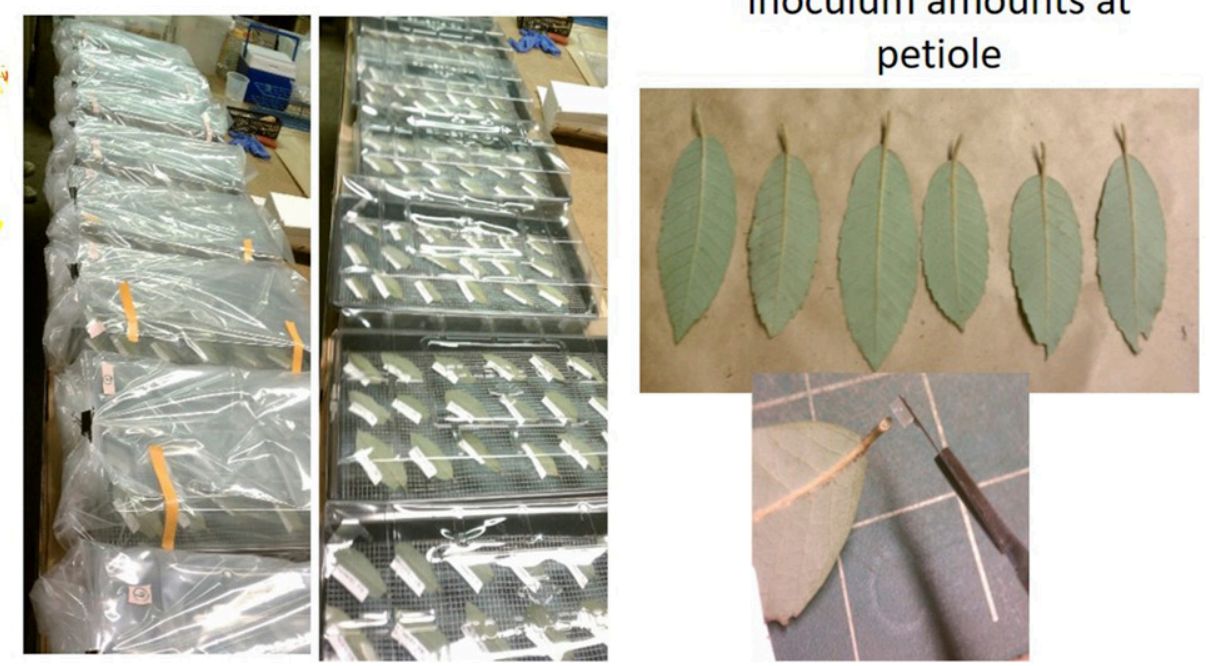

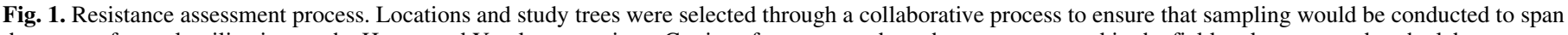

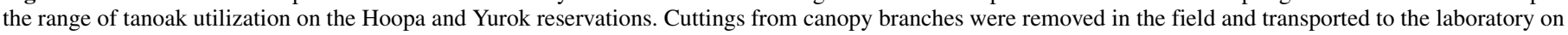

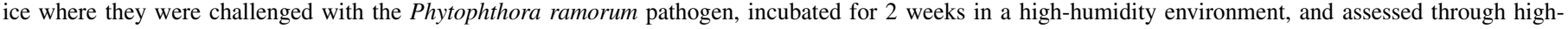
contrast image analysis. 
dominant, or canopy emergent). Within-host resistance measures are most sensitive during late spring, which also corresponds to the seasonal period of greatest pathogen sporulation (Davidson et al. 2011; Hüberli et al. 2012). Therefore, resistance sampling was conducted in a 15-day period between 28 April and 13 May 2014. Tanoak branch samples were cut using an $8-\mathrm{m}$ pole-pruner, placed in water, and stored on ice (approximately $5^{\circ} \mathrm{C}$ ) until lab processing was completed within 60 to $68 \mathrm{~h}$. Sampling occurred on a 3-day running schedule, with one team in the field and a second team in the laboratory. Two sites were sampled at a time with the locations and date selected by random draw. Overall, we assessed resistance on 176 tanoak trees.

Laboratory processing and resistance assays. Tanoak resistance assays were conducted on detached leaves using a methodology which has previously demonstrated a link between resistance to $P$. ramorum measured in leaves and tree sapling survival in common gardens established in areas with high inoculum pressure (Hayden and Garbelotto 2015; Hayden et al. 2011, 2013). At the laboratory, cut tanoak branches were sorted to increase the consistency of leaf length and area as well as to exclude leaves with damage from insects or pathogens. Leaves were cut at the petiole and immediately challenged with a mycelia plug containing $P$. ramorum isolate 1461 , a moderately aggressive isolate which is also representative of the dominant clonal lineages in U.S. forests (Garbelotto and Hayden 2012; Hüberli et al. 2012). Selection of this isolate, as opposed to one from the closest known outbreak, facilitated comparison with preexisting datasets. Care was taken to standardize levels of inoculum introduced in the mycelial plug by standardizing per-plate media volume, using only mycelium at the edge of the plate, and extracting plugs with a $2-\mathrm{ml}$ tool. Five leaves from each tree were challenged with $P$. ramorum while one leaf from each tree was challenged with a sterile agar plug to serve as a reference. Leaves were stored in a darkened, moist chamber at 18 to $20^{\circ} \mathrm{C}$ for 14 days, after which each leaf was photographed, attached to a flat surface, and digitally scanned. Leaf and lesion lengths and areas were quantified using the image analysis program Fiji with the SIOX extension for image segmentation (http://fiji.sc/). Lesion lengths and areas were then standardized to the respective length or area of each leaf, resulting in a relative measure of pathogen growth rate and impact over the 14-day incubation (Fig. 1).

Genetic relatedness and fine-scale spatial genetic structure. We assessed genotypic spatial structure to understand whether relatedness among individuals within each of the study plots could play a role in our observed measures of resistance. DNA was extracted from 8 to 10 leaves from the same pool assessed for resistance assays for each study tree using a simplified cetyltrimethylammonium bromide method (Cullings 1992). Four polymorphic chloroplast DNA (cpDNA) microsatellite loci previously used in tanoak (ucd2, ccmp4, ccmcs5, and rpob) (Nettel et al. 2009) and 11 nuclear DNA (nDNA) microsatellite loci developed for tanoak (LD1, LD3, LD5, LD7, LD8, LD10, LD12, LD13, LD14, LD17, and LD19) (Morris and Dodd 2006) were polymerase chain reaction (PCR) amplified using fluorescent-labeled primers. nDNA primers were multiplexed in five different groups: (i) LD1, LD3, LD7, LD10, and LD14; (ii) LD5 and LD17; (iii) LD12 and LD13; (iv) LD19; and (v) LD8. The PCR cocktail contained $1 \times$ PCR buffer, $2.0 \mathrm{mM} \mathrm{MgCl} 2,0.2 \mathrm{mM}$ each dNTP, $250 \mathrm{nM}$ each reverse primer, $250 \mathrm{nM}$ each fluorescently labeled (FAM or HEX) forward primer, $1 \mathrm{U}$ of Amplitaq polymerase (Invitrogen), and approximately $10 \mathrm{ng}$ of template DNA in a $10-\mu 1$ reaction. Forward and reverse primers for the locus LD3 were run at a final concentration of $400 \mathrm{nM}$, exclusively. For full details of the cpDNA and nDNA amplification procedures, see Nettel et al. (2009). To ensure reproducibility and consistency in PCR amplification, one negative and two positive samples were run as a control for each set of PCR assays and genotyped. All reactions were performed on a Techne (UK) Flexigene thermocycler. PCR product $(0.75 \mu \mathrm{l})$ was mixed with $8 \mu \mathrm{l}$ of formamide and $0.5 \mu \mathrm{l}$ of $500 \mathrm{LIZ}$ size standard (Applied
Biosystems); this cocktail was electrophoresed on an ABI 3730 automated sequencer (Applied Biosystems). Microsatellite alleles were visualized and scored in the program GeneMarker 2.2.0 (Softgenetics).

We checked data quality for scoring errors in nDNA and cpDNA microsatellites using MICRO-CHECKER (Van Oosterhout et al. 2004). We used the same program to estimate the probability of the presence of null alleles in nuclear loci. Chloroplast microsatellite alleles were combined into haplotypes, for which each amplified locus was considered an independent but linked character inherited as a unity. To ascertain reliability of the estimations based on nuclear microsatellites, we tested deviations from Hardy-Weinberg (HW) equilibrium within each population by the inbreeding fixation index, $\mathrm{F}_{\text {IS }}$, with the software FSTAT ver. 2.9.3.2 (Goudet 1995). HW equilibrium could not be rejected for any of the populations. We estimated allelic richness $\left(A_{R}\right)$ and expected heterozygosity $\left(H_{e}\right)$ with FSTAT as measures of within-population genetic diversity.

We took a strict approach of identical multilocus genotypes as indicating clonal identity; this can underestimate the number of clonal copies if somatic mutations have occurred during generations of vegetative reproduction (Dodd et al. 2013). Within each plot, we inferred relatedness using pairwise coefficients calculated for all trees within a site (Lynch and Ritland 1999). This resulted in 1,586 total pairwise comparisons across the entire dataset. We calibrated the coefficients on sets of acorns from an earlier study (R. S. Dodd, unpublished data), where the relatedness among acorns from the same mother tree was at least 0.25 , corresponding to a halfsib relationship.

Statistical analysis of field data. Relative lesion length and area-lesion lengths and areas standardized for respective leaf length and area-were assessed with a combination of linear correlations and linear regression to ensure that persistent effects of leaf area did not confound our relative measures of resistance. Between sites, differences in mean resistance levels (average relative lesion length and lesion area, respectively) were assessed with a one-way analysis of variance using site as the factor. However, variation in resistance within stands could differ considerably, even though mean resistance at the stand level was not statistically different. In this case, a stand with greater variation in resistance could have greater evolutionary potential and, possibly, population-level resilience. Therefore, we repeated this analysis using the estimate of within-stand standard deviation in resistance levels. The distribution of resistance within stands and for the entire sampled population was examined by iteratively fitting to a series of plausible data distributions, including normal, lognormal, Wiebull, and $\gamma$ distributions. Fits were compared with an AIC criterion and when normal or log-normal distributions were found to have the greatest support, these were further assessed with a Kolmogorov test for deviance from a normal distribution using a sensitive decision rule of $P>0.10$. This analysis was repeated for pairwise relatedness within stands, with all values constrained as positive by adding the maximum positive value to each estimate. This step is necessary to evaluate distribution alternative to normal which cannot be fit with negative values; these values were employed in all other analysis, including pairwise relatedness. A series of linear models was employed to assess mean site-level resistance versus stand characteristics, including basal area (by species), density, $A_{R}, H_{e}$, and relative stand attributes, including importance value. At the individual level, relationships of resistance measures and tree basal area, height, canopy position, and tree health rating were assessed with a set of one-factor linear models, where the per-tree estimate of resistance was the average value from five independent measurements (Fig. 1). For each stand or individual-level linear model, the assumptions of normal distribution of residual error and homogeneous variance were assessed and transformed when necessary. We evaluated our dataset for associations between individual tree relatedness and resistance 
measures by contrasting pairwise relatedness values with the absolute difference of relative length and area resistance measures of the same trees using a Pearson's correlation test; this test was conducted for the entire dataset as well as within each site. Additionally, we estimated the degree of spatial correlation among individual tree resistance levels by calculating Moran's $I$ for each resistance measure (relative lesion length or area) within each stand. As an assessment of quality control and assurance, we repeated an analysis performed on a previous study of resistance measured in detached-leaf assays from wild tanoak trees. To compare withinand among-site distribution of variance, a mixed-effects model for lesion-length ratio was constructed to include individual-withinsite, site, and incubation tray-an unavoidable blocking factor introduced by laboratory processing (Fig. 1) —as random effects (Hayden et al. 2011). The significance of each of these sources of variation was tested for statistical significance using model reduction; the resulting $P$ values and variance estimates helped infer whether these factors contributed to the overall variance as well as the proportion of variance associated with each factor. Given that separate models were run on the same data, we reported adjusted $P$ values using a method suitable for limiting the false discovery rate (Benjamini and Hochberg 1995). All data analysis was conducted in R (version 3.1.3; R Core Team), with statistical significance considered where $P \leq 0.05$, unless specified otherwise.

Epidemiological model design, parameterization, and application. We adapted a previously published susceptibleinfected-removed model of sudden oak death disease and host community dynamics to examine the implications management actions to shift within-species variation in resistance and tolerance. The model is based on a previous ordinary differential equation model designed to investigate changes in size class distribution of tanoak within the context of multihost transmission, variable mortality rates, and ongoing recruitment in a simple spatial landscape (Cobb et al. 2012, 2017). Both the previous model and the revised model employed here utilize infection, mortality, and recruitment rates estimated from a regional dataset, and model runs are rendered on a 20-ha landscape with near-distance spatial spread. This model has been adapted as an R package (Sudden Oak Death Dynamics in $\mathrm{R}$ [SODDr]) (https://github.com/noamross/SODDr) in order to increase flexibility in parameterization, host composition, and spatial distribution as well as increase the application to other stand-level forest diseases. Here, the SODDr model was used to gain qualitative insight into three linked questions that arose in light of our measurements of resistance in the field. (i) How could variation in resistance affect overall tanoak host population loss? (ii) How would tolerance versus resistance influence disease dynamics? (iii) What are the implications of manipulating levels of resistance or tolerance at the stand level prior to pathogen invasion? Initial infection rates were static over the course of the simulation and, therefore, our model implicitly assumes that that multigenic and partial resistance would minimize selective pressures on pathogen virulence (DesprezLoustau et al. 2016; Ennos 2015).

Field resistance measures were integrated into the model by adjusting mortality and infection in proportion to variation in relative lesion length or area. We used the mean and range of tanoak infection and mortality rates from a previously published dataset of 2,029 tanoak trees in study sites distributed across the range of disease emergence (an approximately $350-\mathrm{km}$ latitudinal transect). These rates were based on 6 years of annual surveys and were validated against an independent dataset of tanoak infection and mortality rates (Cobb et al. 2012). We related our field measurements of resistance to these tanoak infection and mortality rates by proportionately adjusting (increasing or decreasing) the respective epidemiological model parameters, assuming that the mean and range of resistance was reflected in the same parameters for the field data. This approach is supported by consistency among magnitude and variation in resistance measured in separate field efforts (Hayden et al. 2013, 2011) (this study) as well as consistency of infection and mortality rates among sites given epidemiologically important community-level factors. Our approach makes the additional assumption that previously unexplained variation was due at least in part to unmeasured variation in resistance. Field data were related to epidemiological parameters by calculating deciles of observed resistance frequencies (Fig. 2) and assigning these to the corresponding frequencies of infection and mortality rates observed in the field data. We used this framework to model tanoak host population changes given the observed frequency of resistance levels by adjusting the frequency of individuals within the modeled population as opposed to changing parameter values for mortality or infection rate. The same approach was used to address each of our model-facilitated analysis questions by (i) estimating tanoak population loss given the observed variation in resistance for the entire field dataset, (ii) manipulating infection and mortality rates as linked processes (resistance) versus independent variables (tolerance), and (iii) manipulating the frequency of resistance (or tolerance) to reflect suggested management interventions, specifically selective tanoak removal to increase the proportion of the most resistant trees.

In each set of simulations, we manipulated the epidemiological context by including simulations with California bay laurel (Umbellularia californica), a forest tree that commonly occurs with tanoak and is strongly associated with pathogen spread and disease emergence at local to landscape scales (Cobb et al. 2010; Davidson et al. 2011; Meentemeyer et al. 2011; Rizzo et al. 2005). Of great epidemiological relevance, infection in bay laurel is limited to minor leaf lesions that do not result in negative effects on individual tree health or population dynamics; bay laurel creates a positive epidemiological feedback within stands that amplifies pathogen populations and increases tanoak mortality (Cobb et al. 2010; DiLeo et al. 2009; Garbelotto and Hayden 2012). In light of this, we conducted each model simulation in a multihost transmission scenario or a single-host transmission scenario, reflecting sudden oak death dynamics in stands with bay laurel and tanoak or tanoak alone, respectively. In all cases, total population size of tanoak was held constant and the sole difference between model runs was the population size of a third species that does not interact epidemiologically. This approximates the epidemiological role of several species common in these forests such as redwood (S. sempervirens), Douglasfir (Pseudotsuga menziesii), and big leaf maple (Acer macrophyllum) (Cobb et al. 2012; Davidson et al. 2011). In coastal California forests, most woody species fit into this category because they are either epidemiological dead ends, immune to infection, or have very low competency to transmit infection (Davidson et al. 2011; Meentemeyer et al. 2011; Rizzo et al. 2005). For each model scenario, total, tanoak, and bay laurel population sizes were held constant. Rates of transmission from bay laurel were also held constant across all simulations. Our model included a recovery rate parameter which was set to a low level that remained constant across classes $(0.01)$ (Cobb et al. 2012); therefore, infectious period was driven by mortality rate in our simulations. Finally, for all simulations, transmission was approximated as the rate of infection within host species, a simplification of within-host pathogen population dynamics which matches the scale of the field data employed to parameterize the model (Cobb et al. 2012).

\section{RESULTS}

Measured patterns of resistance. The magnitude and frequency of resistance to Phytophthora ramorum in tanoak measured in this study was similar to that from previous field studies. Tree within plot (repeatability) contributed $30 \%$ of the variation in our dataset and is comparable with previously published values of 27\% (Hayden et al. 2011). An additional 9\% of the variation was associated with the sampled population (Plot), and we found no statistically significant effect of Tray (Table 1). The relatively small amount of variance associated with tree and 
A
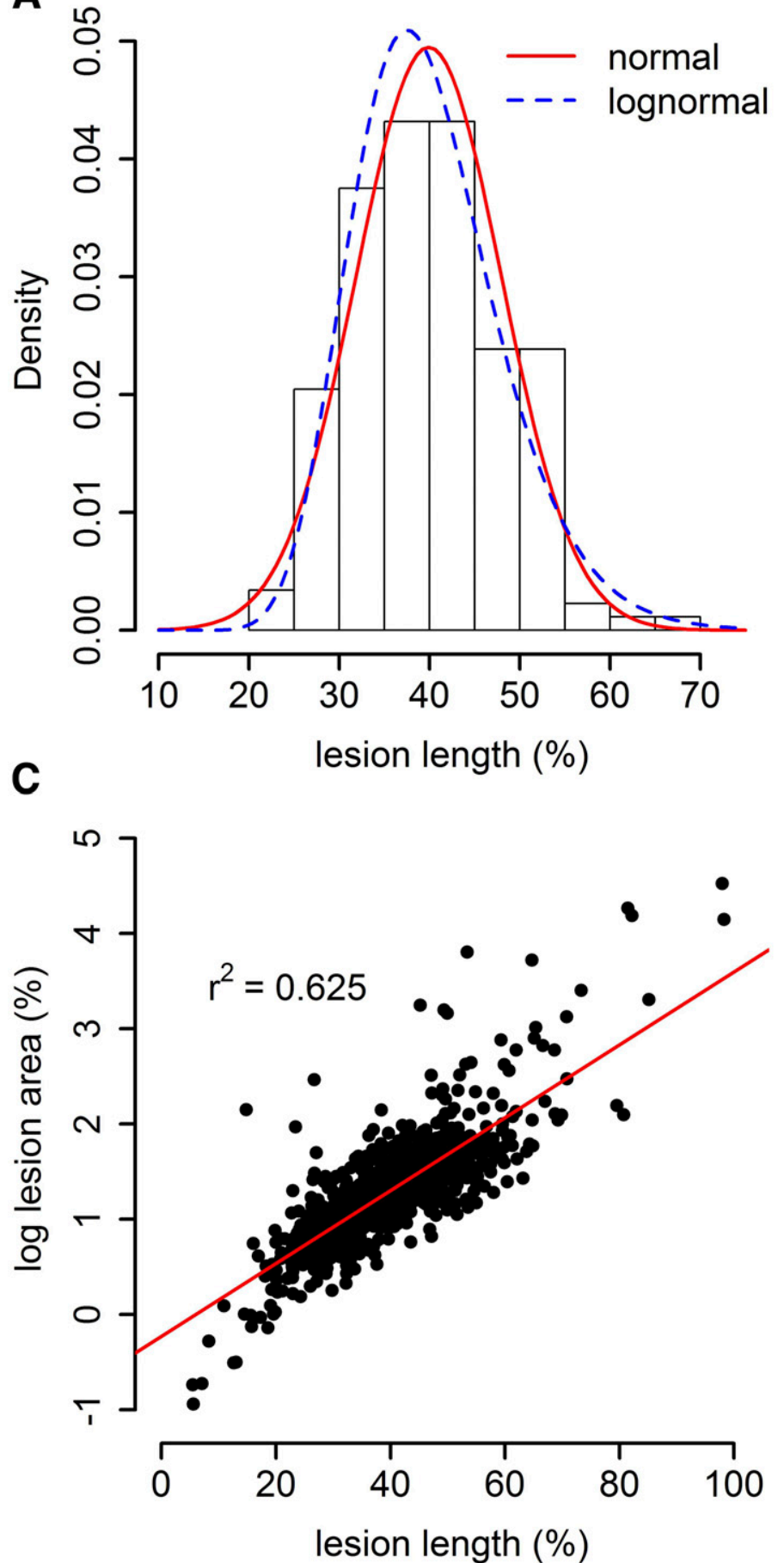
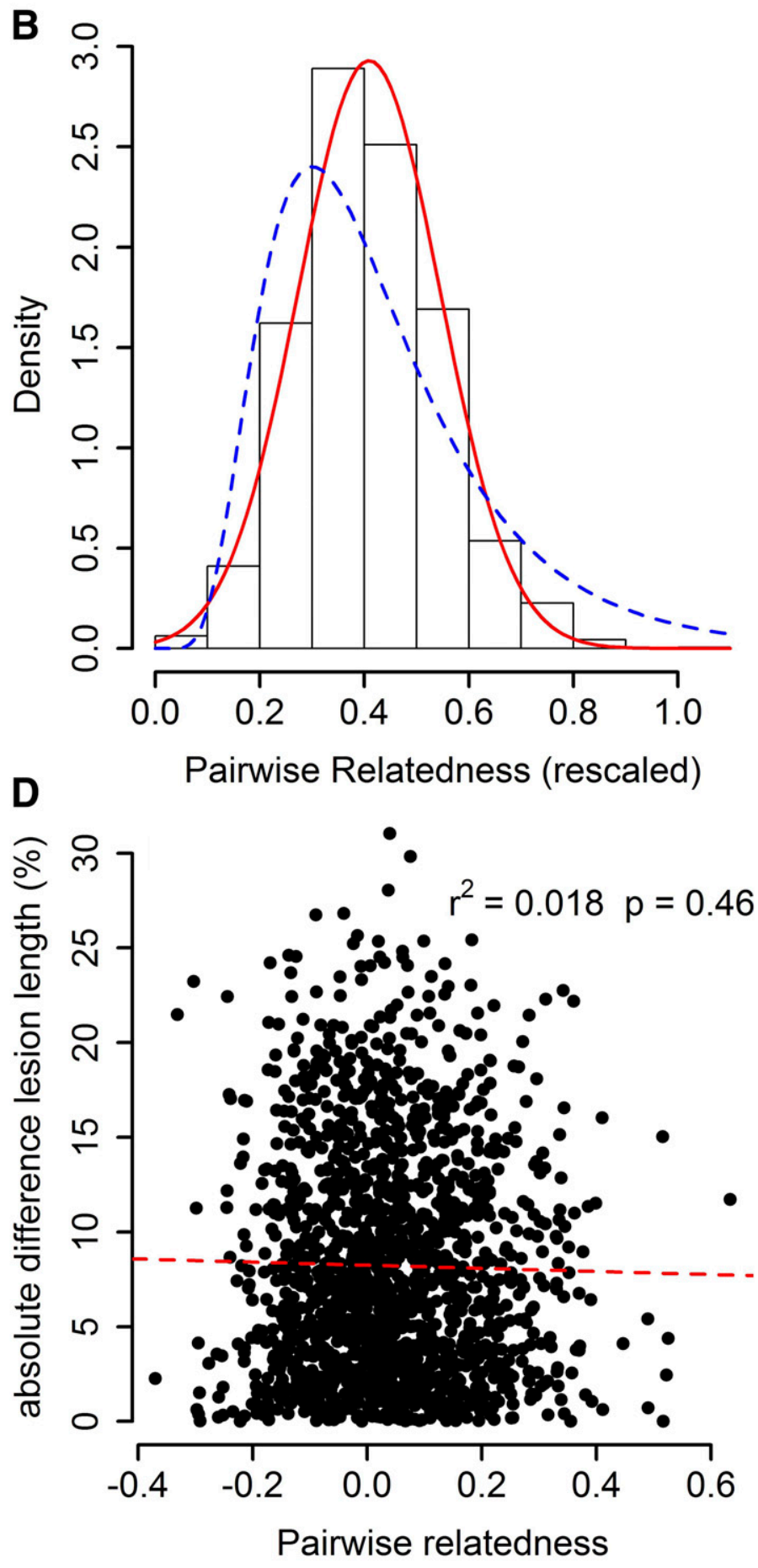

Fig. 2. A, Distribution of resistance within the sampled population; B, distribution of pairwise tree relatedness; $\mathbf{C}$, relationship between resistance measures; and D, regression of pairwise relatedness and pairwise difference in resistance (as lesion length). In A and B, normal (solid line) and lognormal (dashed line) distribution are compared. In $\mathrm{C}$ and $\mathrm{D}$, a solid line indicates a statistically significant $(P<0.05)$ least squares linear relationship whereas a dashed line indicates a nonsignificant relationship (shown for illustration).

TABLE 1. Restricted maximum-likelihood analysis of variance components for field resistance data with levels of replication for each factor $(N)^{\mathrm{a}}$

\begin{tabular}{lrccccrrr}
\hline Source & $N$ & Variance & Standard deviation & $95 \%$ upper & $95 \%$ lower & $\chi^{2}$ & $P$ value & Percent of total \\
\hline Tree in plot & 176 & 39.4049 & 6.2773 & 5.5124 & 7.1327 & 130.26 & $<0.0001$ \\
Plot & 10 & 12.0495 & 3.4712 & 1.9257 & 5.3332 & 58.41 & $<0.0001$ & 30.13 \\
Tray & 14 & 0.7612 & 0.8725 & 0.0000 & 1.7588 & 1.34 & 0.25 & N \\
Residual & NA & 78.5869 & 8.8649 & 8.4881 & 9.2716 & NA & NA & 60.09 \\
\hline
\end{tabular}

a Significance tests for random factors were conducted by model reduction of maximum likelihood estimates. NA = not applicable. 
TABLE 2. Linear analysis of site and tree factor influences on measures of tanoak resistance to Phytophthora ramorum ${ }^{\mathrm{a}}$

\begin{tabular}{|c|c|c|}
\hline \multirow[b]{2}{*}{ Parameter } & \multicolumn{2}{|c|}{ Resistance measure } \\
\hline & Mean & Variance \\
\hline \multicolumn{3}{|l|}{ Tree-level factors } \\
\hline \multicolumn{3}{|l|}{ Lesion area } \\
\hline $\operatorname{Max} \mathrm{dbh}(\mathrm{cm})^{\mathrm{b}}$ & 0.268 & NA \\
\hline Basal area $\left(\mathrm{m}^{2}\right)$ & 0.268 & NA \\
\hline Height (m) & 0.63 & NA \\
\hline Canopy position & 0.63 & NA \\
\hline Health rating & 0.543 & NA \\
\hline \multicolumn{3}{|l|}{ Lesion length } \\
\hline $\operatorname{Max} \mathrm{dbh}(\mathrm{cm})^{\mathrm{b}}$ & 0.826 & NA \\
\hline Basal area $\left(\mathrm{m}^{2}\right)$ & 0.826 & NA \\
\hline Height (m) & 0.826 & NA \\
\hline Canopy position & 0.826 & NA \\
\hline Health rating & 0.826 & NA \\
\hline \multicolumn{3}{|l|}{ Stand-level factors } \\
\hline \multicolumn{3}{|l|}{ Lesion area } \\
\hline Basal area $\left(\mathrm{m}^{2} \mathrm{ha}^{-1}\right)$ & 0.468 & 0.648 \\
\hline Density $\left(\mathrm{ha}^{-1}\right)$ & 0.573 & 0.648 \\
\hline Tanoak IV & 0.468 & 0.648 \\
\hline PSME IV ${ }^{\mathrm{d}}$ & 0.468 & 0.648 \\
\hline Allelic richness & 0.728 & 0.871 \\
\hline Heterozygosity & 0.728 & 0.648 \\
\hline \multicolumn{3}{|l|}{ Lesion length } \\
\hline Basal area $\mathrm{m}^{2} \mathrm{ha}^{-1}$ & 0.302 & 0.782 \\
\hline Density $\mathrm{ha}^{-1}$ & 0.536 & 0.782 \\
\hline Tanoak IVc & 0.17 & 0.792 \\
\hline PSME IV ${ }^{d}$ & 0.17 & 0.782 \\
\hline Allelic richness & 0.536 & 0.782 \\
\hline Heterozygosity & 0.563 & 0.782 \\
\hline
\end{tabular}

a No statistically significant parameter treatment parameters $(P \leq 0.05)$ were found. Multiple comparison adjusted $P$ values are reported (see Methods). For tree-level factors, $N=176$, and for stand-level factors, $N=10$. Standlevel analysis included linear models designed to test for differences in the levels of variance in resistance among sites, where variance was estimated as the standard deviation of resistance measures among study trees within site; the analogous parameter is not applicable at the individual tree level. NA = not applicable.

b Maximum diameter at breast height.

c Importance value (IV) is calculated as relative density + relative basal area expressed in percentage.

${ }^{\mathrm{d}}$ PSME = Pseudotsuga menziesii (Douglas Fir). PSME IV was square root transformed to meet model assumptions.

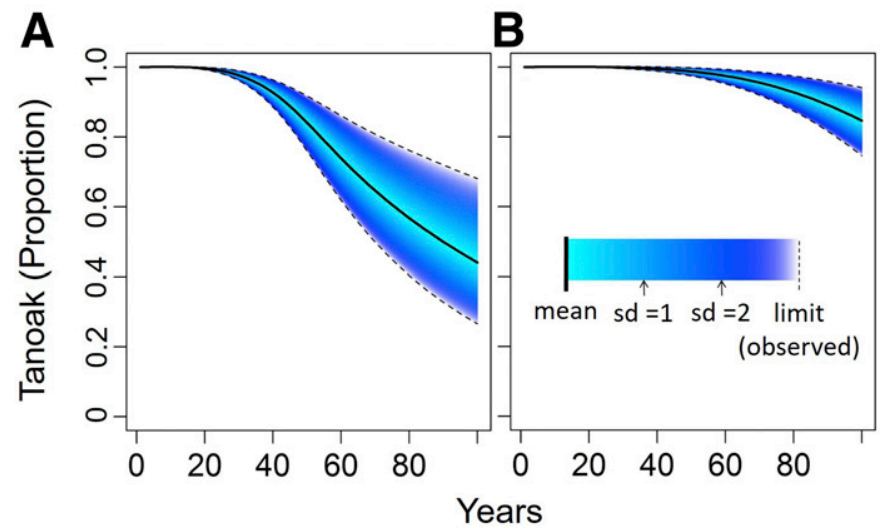

Fig. 3. Model estimates of tanoak host population decline across resistance phenotypes for $\mathbf{A}$, stands with two species transmitting the pathogen and $\mathbf{B}$, stands with a single species transmitting the pathogen. Model results are presented for the continuum of observed resistance levels and presented as the population mean (solid black line) and the limit of greatest or least observed resistance (dashed black lines). All values of resistance are shown along a continuum of the observed (normal) distribution of resistance levels; the first and second standard deviations of the mean (sd) are indicated on the shading ramp. For each model result, total host population size is equal. population suggests that much of the variation in resistance was due to factors not encompassed by our statistical design. Our two measures of resistance, leaf lesion area and lesion length, showed consistent patterns across measurements at the leaf and tree level. When each measure was standardized for leaf length or area, lesion length and log-transformed lesion area were significantly and linearly related $\left(r^{2}=0.625, P=0.008\right)$ (Fig. 2). Within and between sites, the frequencies of standardized resistance measures were normal and log-normal for proportional lesion length or area, respectively, although goodness of fit for the respective measurements suggested that both distributions had similar support (Fig. 2B). Kolmogorov tests indicated the fitted distributions were not significantly different than normal for relative lesion length and logtransformed relative lesion area. We found the greatest support for a normal distribution of pairwise host relatedness but poor support of a lognormal distribution (Fig. 2A and B). We found no significant associations between resistance measures for pairs of individual trees and their corresponding relatedness (Fig. 2D). No significant correlations for relative lesion length or area were found for the overall dataset or within individual study sites.

At all 10 sites, Moran's I values for standardized lesion area showed no support for clustered or overdispersed spatial distribution. However, we found support for clustering of standardized lesion length at one site (Moran's $I=0.17, P=0.003$ ) and evidence of overdispersal at a second site (Moran's $I=-0.21, P=0.021$ ); all eight other sites had no evidence of clustering and the balance of evidence suggested that resistance tended to follow spatially random distribution.

Stand associations with resistance. Across individual trees, resistance measures (lesion area and length) showed no significant relationships to tree basal area, canopy position, tree height, or tree health rating (Table 2). Results were similar for the investigation of linear relationships between resistance measures and stand structure or genetic diversity across sites (Table 2). Although one site had significantly lower mean proportion lesion length relative to the others, this appears to be somewhat idiosyncratic; mean resistance across sites was not significantly associated with stand density, basal area, $A_{R}, H_{e}$, or variation in dominance by any overstory canopy species (Table 2). Within stands, variation in resistance-as approximated by stand-level standard deviation of standardized lesion area and length-lacked any statistically significant relationship to any of our measured variables of stand structure (Table 2).

Model analysis-How does variation in resistance affect tanoak population loss? Model simulations showed substantial effects of resistance on patterns of tanoak population decline but these effects were magnified when a second sporulation supporting species was present in the modeled stand. When simulations included a second host that supports transmission but suffers no negative impacts of infection (e.g., bay laurel), the tanoak populations declined more rapidly and reached lower levels at the end of the model simulation (Fig. 3). The greater range of expected survival times by the end on the simulation for multihost transmission stands occurred even though epidemiological parameters and host population sizes were identical across the two scenarios (Fig. 3). These simulations also showed two additional but related implications of the normal distribution of resistance: the most- and least-resistant individuals were relatively rare and most expected survival times were within first standard deviation of measured resistance levels (Fig. 3, light-shaded region).

Model analysis-Resistance versus tolerance and modeled management actions. The resistance versus tolerance assumption influenced both infected tanoak and total tanoak population sizes, although the implications of the assumption varied across the two epidemiological scenarios (Fig. 4). Regardless of the mechanism, (resistance or tolerance), slowing mortality rates resulted in reduced disease impacts on tanoak population sizes by the end of the simulations but the impacts on pathogen prevalence 
were more complicated and nuanced. In the multihost scenario, simulating tolerance or resistance resulted in similar levels of tanoak population loss and prevalence of infection by the end of the simulation (Fig. 4). Specifically, the proportion of surviving tanoak in the high-tolerance scenario was 0.62 compared with 0.64 in the high-resistance scenario, and 0.29 versus 0.26 for the corresponding low-tolerance and -resistance scenarios, respectively (Fig. 4A). Corresponding proportions of tanoak infected were 0.78 versus 0.77 and 0.34 versus 0.32 for the same comparisons (Fig. 4B). In this simulation, both tolerance and resistance had equal value in terms of conserving tanoak, with the same costs of increased infection prevalence. However, in the single-species simulations, infection prevalence reached the highest levels in stands with the greatest prevalence of high-tolerance individuals, likely because the longer survival time of infected tanoak led to an accumulation of pathogen within the modeled stand (Fig. 4C and D). Although differences in final proportion surviving between high- and low-tolerance simulations for the single species scenario were trivial ( 0.86 versus 0.84 ), the high-tolerance scenario had substantially greater prevalence of infected hosts compared with the low-tolerance scenario ( 0.52 versus 0.23$)$. These relative patterns were the inverse of that between high resistance versus low resistance $(0.16$ versus 0.32). In the single-species scenario, high tolerance led to the greatest stand-level pathogen accumulation. In either epidemiological context, the high-resistance and single-species transmission epidemiological scenario resulted in the lowest mortality and infection prevalence compared with all other scenarios.

\section{DISCUSSION}

Endemic tree resistance to invasive pathogens is a management resource even when this resistance is partial and no focal hosts are immune. Multigenic resistance and genetic variation within host populations can reduce selective pressures that increase pathogen virulence and lead to more durable resistance benefits (DesprezLoustau et al. 2016; Ennos 2015; Mundt 2014). In a population of culturally important tanoak, our study suggests that a small but consistent portion of these trees across several ecologically different study sites had relatively high resistance. Given that this finding is consistent with several other field studies, it implies that the highest levels of resistance occur in most stands, even if they do not appear to occur at high frequency in any particular stand. Unfortunately, this and previous field studies of tanoak resistance to $P$. ramorum found no significant associations between resistance and easily measured or manipulated individual or stand variables, which makes practical implementation labor intensive (Table 2). From a management perspective, the most intriguing aspect of our empirical results lies in the normal distribution of resistance frequency within stands, as well as the consistency of these distributions across stands. Model simulations of management to manipulate resistance within stands suggests that these patterns hold utility for conservation of cultural resources. However, our field data do not resolve whether our measured differences in pathogen growth rate in detached leaves influences sporulation (and transmission) rates. Although within-host pathogen growth rate has been shown to be a good approximation of resistance in models and reflects host competency in bay laurel, we caution that the assumption has not yet been tested in tanoak (Hüberli et al. 2012; Roy and Kirchner 2000). Whether the characteristic we measured in the laboratory reflects a link between both transmission and mortality will determine the epidemiological costs and benefits of preinvasion changes in resistance distribution and, thus, where its manipulation will be appropriate (Fig. 4).

We found no individual or stand-level characteristics associated with resistance (Table 2), a disappointing though expected set of "negative results". Previous studies of tanoak resistance to $P$. ramorum in natural populations have also failed to detect significant relationships between resistance and any other readily measured plant characteristics, including leaf size or shape, amounts of insect or other pathogen damage, or other leaf surface characteristics (Hayden et al. 2011, 2013). If readily measured and manipulated characteristics of individual tanoak trees and stands such as size, species composition, or overall health rating could be linked to resistance, this would have great management utility; however, we found no evidence of a relationship between these factors and resistance as we measured it (Table 2). Currently, the laboratory assays reported here are the only means of identifying resistance (Hayden and Garbelotto 2015; Hayden et al. 2013) and the preponderance of spatially random patterns of resistance further increases the sampling burden when locating the most resistant trees within stands is the goal. In previous studies, the leaf assay demonstrated utility for predicting survival of relatives but much variation in survival remained unexplained (Hayden et al. 2013). Among other contributing factors, it is likely that the assay does not measure all components of resistance, and a different assay may yet yield different results. Furthermore, these assays are timeconsuming measures with seasonal sensitivity (Hüberli et al. 2012). Given the lack of overt tree characteristics linked to the resistance phenotype, including our microsatellite marker analysis, technological innovations that use metabolic biomarkers or a molecular detection method based on or tightly linked with the set of genes responsible for the partial resistance phenotype will help make endemic resistance of more practical utility. Identification of specific genes linked to the resistance phenotype might also provide information on resistance durability and the potential for deploying resistant nursery stock (Mundt 2014). In this study, we did not find significant associations between resistance measures within stands (mean and variance) with $A_{R}$ and $H_{e}$. We also did not find any significant associations between relatedness and resistance measures across pairwise comparisons of sets of trees (Fig. 2). However, our assessment of genetic diversity within stands utilized a relatively rapid, inexpensive, and neutral marker approach that is unlikely to pinpoint multigenic resistance phenotypes.

We used a set of models to better understand the implications of normally distributed frequency of resistance within stands. In the

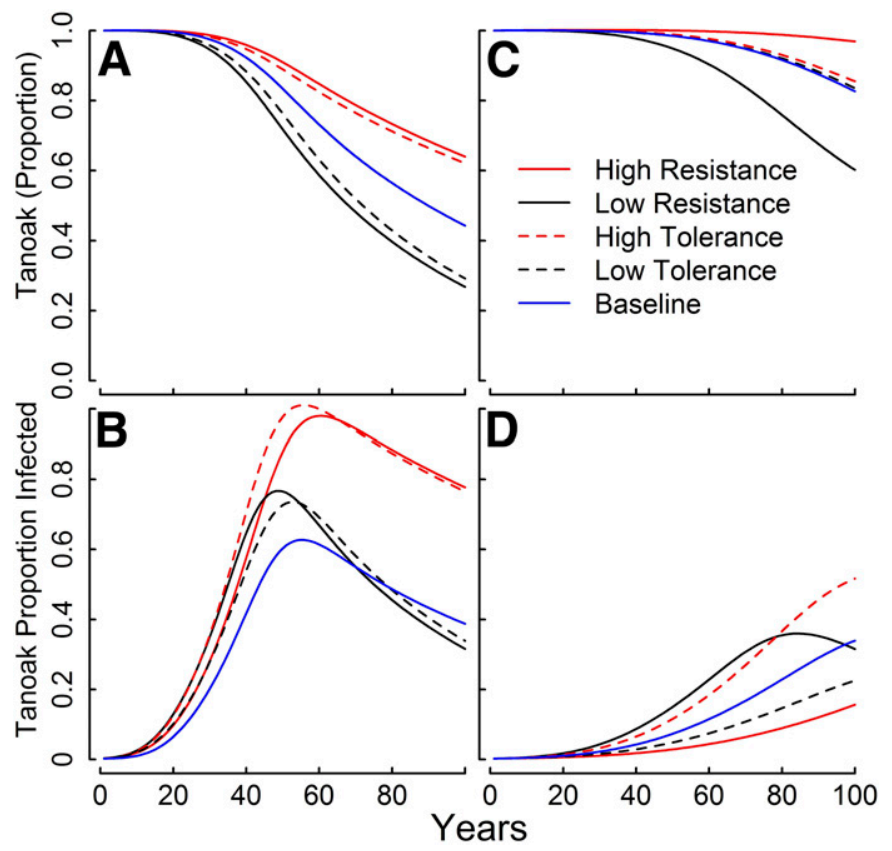

Fig. 4. Model assessment of the resistance versus tolerance assumptions for $\mathbf{A}$ and $\mathbf{B}$, stands with two species transmitting the pathogen and $\mathbf{C}$ and $\mathbf{D}$, stands with a single species transmitting the pathogen. Model results are presented as total population size (top row) and number of infected target hosts (bottom row). The "Baseline" scenario (dark solid line) represents a hypothetical condition where the resistance phenotype is evenly distributed across 10 resistance categories. For each model result, total host population size is equal. 
model, resistance patterns become more important in determining tanoak survival for high-inoculum stands over time (Fig. 3). This pathogen-mediated selection is likely to increase the proportion of resistant individuals as disease progresses, an effect which could contribute to the range of survival times and extent of tanoak mortality in natural stands (Cobb et al. 2012; Metz et al. 2012). Tanoak individuals can be very abundant within stands; for example, approximately 980 trees $\mathrm{ha}^{-1}$ for mixed evergreen and approximately 411 trees ha ${ }^{-1}$ for redwood forest types (Metz et al. 2012). However, the most resistant trees can only be expected to account for approximately 16 and 7 trees ha ${ }^{-1}$, respectively, based on their frequency observed in this study (Fig. 2). Although finding the most resistant trees in a mixed population would remain a "needle in a haystack" problem, the simulations with observed resistance frequencies (Fig. 3) suggest that these individuals will become more apparent over the course of disease as less resistant trees are removed more quickly. Resistance surveys focused on highly disease-impacted stands may accelerate identification of the most resistant individuals for further use in a breeding program and stands, in contrast to sampling in uninvaded stands conducted here, which is directed at protecting current resources.

We caution that all resistance which has been measured thus far is partial, meaning even the most resistant trees can be expected to be lost in high-inoculum conditions (Cobb et al. 2012; Metz et al. 2012) (Fig. 4). Therefore, even where the most resistant tanoak have been identified (such as in our study sites), management to decrease overall inoculum levels, currently or in the future, is likely to be required to protect the individual trees over the long term. Our main purpose in this study was to confront the immediate problem: how do we conserve threatened cultural resources given the time required to develop resistance development through breeding programs? Although labor intensive, silvicultural treatments to increase the prevalence of the most resistant trees while reducing potential inoculum overall is a two-factor approach that holds promise to create stands with resilient tanoak populations and the associated unique ecological functions and cultural value of this species by driving host population sizes below thresholds needed for pathogen persistence or invasion (Carroll et al. 2014; Cobb et al. 2012; Holt et al. 2003). Previously reported evidence of host population outbreak thresholds support this approach, given that model simulations with low tanoak density (70 tanoak trees ha-1) appeared to be resilient to pathogen invasion (Cobb et al. 2012). These simulations were conducted with average infection and mortality rates but decreasing these parameters would increase critical population size thresholds in the model (Cobb et al. 2013). The utility of this approach is tempered by the unresolved assumption of tolerance versus resistance because pathogen accumulation in stands with increased prevalence of tolerant trees could defeat management focused on keeping pathogen populations low (Fig. 4D). However, increased tolerance in tanoak populations would help maintain the tree's cultural and ecological value in mixed-host stands, where the same level of cultural and ecological value is often ascribed to bay laurel. Furthermore, variation in bay laurel susceptibility has been documented (Hüberli et al. 2012), suggesting that our model simulations could overestimate transmission rate from bay laurel in real stands. We are optimistic that treatments which result in greater tanoak resiliency are justified by our study, and stand-level experiments are the next step for increasing our understanding of when and where treatment benefits outweigh expense and avoid counterproductive outcomes.

Partial resistance at the frequency and levels measured in our field survey of tanoak is unlikely to be a suitable strategy on its own but, in other disease systems where resistance is stronger or more prevalent, the approach could result in resilient populations in specific locations or over time (Roy and Kirchner 2000). In light of this, it is important to note that, even though we measured resistance at multiple stands and at a relatively large spatial scale, this study is hardly a complete sample of the genetic, ecological, and geographical variation of tanoak. Our empirical resistance data has a similar range and average compared with previous studies but it remains possible that greater resistance levels could be found elsewhere for tanoak, justifying continued survey. However, developing a comprehensive dataset on resistance is a challenge for tanoak just as it would be for any broadly distributed host where the characteristic of interest is difficult to measure.

Application of endemic resistance as a stand management tool faces the same practical barriers to application across ecosystems as it does in our case study of tanoak; resistance must be readily detectable and durable (Mundt 2014), and resistance versus tolerance can affect the utility in different epidemiological scenarios. For tanoak and sudden oak death, our results suggest that endemic resistance alone will not be sufficient for combating the disease. However, both on and outside of lands managed by indigenous people, management actions are rarely applied alone. Instead, tree removal, fire, and other actions are applied to alter species composition and size class distribution in the service of creating desired fire resiliency or resource provisioning (Lake et al. 2017). Although resistance remains labor intensive to detect, we surveyed a total of 3.6 ha, suggesting that surveys could be successively compiled into a scale relevant to management and could be leveraged with other ongoing land management activities such as thinning and fire. California and Oregon indigenous communities place high importance on tanoak resources and, for these communities, sudden oak death is an alarming and immediate problem. Although breeding for resistance offers a pathway for increasing tanoak resiliency over the long term, it cannot arrest immediate loss of cultural resources. In turn, losses of cultural resources can exacerbate isolation, alienation, and loss of identity within communities, problems which are associated with even more devastating social problems, including suicide and addiction (Turner et al. 2008). Partial resistance is unlikely to prevent cultural losses on its own but, combined with additional management actions, it is a potential tool for chipping away at sudden oak death, a problem that has proved intractable with single-treatment or strategic approaches (Cunniffe et al. 2016; Lee et al. 2012). In the face of pathogens with large host ranges more broadly, responses tailored to epidemiological intricacies which also reflect specific management or conservation goals have a much greater likelihood of successful protection of at-risk forest resources.

\section{ACKNOWLEDGMENTS}

We thank T. Gist, F. Hunsucker, R. Reed, J. Lindsay, J. Erler, F. Lake, O. Parrish, and N. Hapner for their guidance in understanding tanoak resources within tribal communities, help in locating and establishing field study sites, and many other aspects of facilitating resistance sampling on tribal lands; M. Beh, H. Mehl, and T. Popenuk for help with field and laboratory processing of plant samples; two anonymous reviewers who graciously offered two rounds of comments that improved the article; and J. Scott for important feedback.

\section{LITERATURE CITED}

Benjamini, Y., and Hochberg, Y. 1995. Controlling the false discovery rate: A practical and powerful approach to multiple testing. J. R. Stat. Soc. B 57:289-300.

Best, A., White, A., and Boots, M. 2014. The coevolutionary implications of host tolerance. Evolution 68:1426-1435.

Bowcutt, F. 2011. Tanoak target: The rise and fall of herbicide use on a common native tree. Environ. Hist. 16:197-225.

Bowcutt, F. 2013. Tanoak landscapes: Tending a Native American nut tree. Madrono 60:64-86.

Carroll, S. P., Jørgensen, P. S., Kinnison, M. T., Bergstrom, C. T., Denison, R. F., and Gluckman, P. 2014. Applying evolutionary biology to address global challenges. Science 346:1245993.

Cobb, R. C., Filipe, J. A. N., Meentemeyer, R. K., Gilligan, C. A., and Rizzo, D. M. 2012. Ecosystem transformation by emerging infectious disease: Loss of large tanoak from California forests. J. Ecol. 100:712-722.

Cobb, R. C., Hartsough, P., Ross, N., Klein, J., LaFever, D. H., Frankel, S. J., and Rizzo, D. M. 2017. Resiliency or restoration: Management of sudden oak death before and after outbreak. For. Phytophthoras 7:1-14. 
Cobb, R. C., Meentemeyer, R. K., and Rizzo, D. M. 2010. Apparent competition in canopy trees determined by pathogen transmission rather than susceptibility. Ecology 91:327-333.

Cobb, R. C., Rizzo, D. M., Hayden, K. J., Garbelotto, M., Filipe, J. A. N., and Gilligan, C. A. 2013. Biodiversity conservation in the face of dramatic forest disease: An integrated conservation strategy for tanoak (Notholithocarpus densiflorus) threatened by sudden oak death. Madrono 60:151-164.

Cullings, K. 1992. Design and testing of a plant-specific PCR primer for ecological and evolutionary studies. Mol. Ecol. 1:233-240.

Cunniffe, N. J., Cobb, R. C., Meentemeyer, R. K., Rizzo, D. M., and Gilligan, C. A. 2016. Modeling when, where, and how to manage a forest epidemic, motivated by sudden oak death in California. Proc. Natl. Acad. Sci. USA 113:5640-5645

Davidson, J. M., Patterson, H. A., Wickland, A. C., Fichtner, E. J., and Rizzo, D. M. 2011. Forest type influences transmission of Phytophthora ramorum in California oak woodlands. Phytopathology 101:492-501.

Desprez-Loustau, M.-L., Aguayo, J., Dutech, C., Hayden, K. J., Husson, C., and Jakushkin, B. 2016. An evolutionary ecology perspective to address forest pathology challenges of today and tomorrow. Ann. For. Sci. 73:45-67.

DiLeo, M. V., Bostock, R. M., and Rizzo, D. M. 2009. Phytophthora ramorum does not cause physiologically significant systemic injury to California bay laurel, its primary reservoir host. Phytopathology 99:1307-1311.

Dodd, R. S., Mayer, W., Nettel, A., and Afzal-Rafii, Z. 2012. Clonal growth and fine-scale genetic structure in tanoak (Notholithocarpus densiflorus: Fagaceae). J. Hered. 104:105-114.

Dodd, R. S., Nettel, A., Wright, J. W., and Afzal-Rafii, Z. 2013. Genetic structure of Notholithocarpus densiflorus (Fagaceae) from the species to the local scale: A review of our knowledge for conservation and replanting. Madrono 60:130-138.

Ennos, R. A. 2015. Resilience of forests to pathogens: An evolutionary ecology perspective. Forestry 88:41-52.

Filipe, J. A. N., Cobb, R. C., Meentemeyer, R. K., Lee, C. A., Valachovic, Y. S., and Cook, A. R., Rizzo, D. M., and Gilligan, C. A. 2012. Landscape epidemiology and control of pathogens with cryptic and long-distance dispersal: Sudden oak death in Northern Californian forests. PLOS Comput. Biol. 8:e1002328.

Freinkel, S. 2007. American Chestnut: The Life, Death, and Rebirth of a Perfect Tree. University of California Press, Berkeley, CA.

Garbelotto, M., and Hayden, K. J. 2012. Sudden oak death: Interactions of the exotic oomycete Phytophthora ramorum with naive North American hosts. Eukaryot. Cell 11:1313-1323.

Goudet, J. 1995. FSTAT (Version 1.2): A computer program to calculate Fstatistics. J. Hered. 86:485-486.

Hansen, E. M., Kanaskie, A., Prospero, S., McWilliams, M., Goheen, E. M., and Osterbauer, N. 2008. Epidemiology of Phytophthora ramorum in Oregon tanoak forests. Can. J. For. Res. 38:1133-1143.

Harrington, T. B., and Tappeiner, J. C. 2009. Long-term effects of tanoak competition on Douglas-fir stand development. Can. J. For. Res. 39: 765-776.

Hayden, K., and Garbelotto, M. 2015. PROTOCOL 02-11.1: Detached leaf inoculation for tanoak. Pages 1-3 in: Laboratory Protocols for Phytophthora Species. Online publication. The American Phytopathological Society. https://apsjournals.apsnet.org/doi/10.1094/9780890544969.02.11.1

Hayden, K. J., Garbelotto, M., Dodd, R., and Wright, J. W. 2013. Scaling up from greenhouse resistance to fitness in the field for a host of an emerging forest disease. Evol. Appl. 6:970-982.

Hayden, K. J., Nettel, A., Dodd, R. S., and Garbelotto, M. 2011. Will all the trees fall? Variable resistance to an introduced forest disease in a highly susceptible host. For. Ecol. Manage. 261:1781-1791.

Holt, R. D., Dobson, A. P., Begon, M., Bowers, R. G., and Schauber, E. M. 2003. Parasite establishment in host communities. Ecol. Lett. 6:837-842.
Hüberli, D., Hayden, K. J., Calver, M., and Garbelotto, M. 2012. Intraspecific variation in host susceptibility and climatic factors mediate epidemics of sudden oak death in western US forests. Plant Pathol. 61:579-592.

Lake, F. K., Wright, V., Morgan, P., McFadzen, M., McWethy, D., and Stevens-Rumann, C. 2017. Returning fire to the land: Celebrating traditional knowledge and fire. J. For. 115:343-353.

Lee, C. A., Alexander, J. M., Frankel, S. J., and Valachovic, Y. 2012. Evolution of an invasive species research program and implications for large-scale management of a non-native, invasive plant pathogen. Environ. Nat. Resour. Res. 2:99-111.

Lynch, M., and Ritland, K. 1999. Estimation of pairwise relatedness with molecular markers. Genetics 152:1753-1766.

Maloy, O. C. 1997. White pine blister rust control in North America: A case history. Annu. Rev. Phytopathol. 35:87-109.

Mascheretti, S., Croucher, P., Vettraino, A., Prospero, S., and Garbelotto, M. 2008. Reconstruction of the sudden oak death epidemic in California through microsatellite analysis of the pathogen Phytophthora ramorum. Mol. Ecol. 17:2755-2768.

Meentemeyer, R. K., Cunniffe, N. J., Cook, A. R., Filipe, J. A. N., Hunter, R. D., and Rizzo, D. M. 2011. Epidemiological modeling of invasion in heterogeneous landscapes: Spread of sudden oak death in California (19902030). Ecosphere 2 (Article 17):1-24.

Metz, M. R., Frangioso, K. M., Wickland, A. C., Meentemeyer, R. K., and Rizzo, D. M. 2012. An emergent disease causes directional changes in forest species composition in coastal California. Ecosphere 3: (Article 86):1-23.

Morris, V. R. F., and Dodd, R. S. 2006. Characterization of microsatellite markers for the tanoak tree, Lithocarpus densiflorus. Mol. Ecol. Notes 6: 706-708.

Mundt, C. C. 2014. Durable resistance: A key to sustainable management of pathogens and pests. Infect. Genet. Evol. 27:446-455.

Nettel, A., Dodd, R., and Afzal-Rafii, Z. 2009. Genetic diversity, structure, and demographic change in tanoak, Lithocarpus densiflorus (Fagaceae), the most susceptible species to sudden oak death in California. Am. J. Bot. 96: 2224-2233.

Rizzo, D. M., Garbelotto, M., and Hansen, E. M. 2005. Phytophthora ramorum: Integrative research and management of an emerging pathogen in California and Oregon forests. Annu. Rev. Phytopathol. 43:309-335.

Roy, B. A., and Kirchner, J. W. 2000. Evolutionary dynamics of pathogen resistance and tolerance. Evolution 54:51-63.

Smith, K. F., Sax, D. F., and Lafferty, K. D. 2006. Evidence for the role of infectious disease in species extinction and endangerment. Conserv. Biol. 20:1349-1357.

Sniezko, R. A. 2006. Resistance breeding against nonnative pathogens in forest trees-Current successes in North America. Can. J. Plant Pathol. 28: S270-S279.

Thompson, R. N., Cobb, R. C., Gilligan, C. A., and Cunniffe, N. J. 2016. Management of invading pathogens should be informed by epidemiology rather than administrative boundaries. Ecol. Modell. 324:28-32.

Turner, N., Gregory, R., Brooks, C., Failing, L., and Satterfield, T. 2008. From invisibility to transparency: Identifying the implications. Ecol. Soc. 13:7. Online publication. https://www.ecologyandsociety.org/vol13/iss2/art7/ main.html\#cultural

Valachovic, Y., Quinn-Davidson, L., Lee, C., Goldsworthy, E., and Cannon, P. 2013. Novel approaches to SOD management in California wildlands: A case study of "eradication" and collaboration in Redwood Valley. Pages 99-107 in: Proc. Sudden Oak Death Fifth Sci. Symp.

Van Oosterhout, C., Hutchinson, W. F., Wills, D. P. M., and Shipley, P. 2004. micro-checker: Software for identifying and correcting genotyping errors in microsatellite data. Mol. Ecol. Notes 4:535-538.

Waterman, T. T. 1920. Yurok Geography. University of California Press, Berkeley. 